\title{
Child abuse: we have problems
}

\author{
Peter J. Strouse ${ }^{1}$
}

Received: 12 January 2016 / Accepted: 17 January 2016 / Published online: 17 February 2016

(C) Springer-Verlag Berlin Heidelberg 2016

Child abuse exists. This is the paramount problem. According to the U.S. Department of Health and Human Services there were 678,932 cases of child abuse and neglect in the United States in 2013 [1]. Eighteen percent of these children suffered from physical abuse [1]. Many of these children also suffered neglect or sexual abuse. There were 9.1 victims per 1,000 children in 2013 [1]. For infants ( $<1$ year old) the number was 23.1 victims per 1,000 children [1]. The estimated number of deaths from child abuse in the United States in 2013 was 1,520 [1]. In addition to the children who die, many more are left with permanent neurological damage from abusive neurotrauma $[2,3]$. The cost of lifetime care for these victims is enormous $[4,5]$. In addition to the children who die or are left physically or mentally handicapped, innumerable others suffer psychological injury [6]. Many inhabitants of our prisons were victims of abuse as a child [7, 8]. Unfortunately, people who are abused as a child have an increased likelihood of becoming abusers themselves as adults [9].

Child abusers tear families apart — not hospital child protection teams, child abuse pediatricians and governmental child protective services. It's the abusers. This is a problem. When child abuse occurs within a family unit, there is no easy solution. Regardless of compassionate efforts by professionals to properly care for and protect the child and the family, the abuser's damage is done and cannot be ignored or quickly

Peter J. Strouse

Rad-Ped-Radiol-Journal@med.umich.edu

1 Section of Pediatric Radiology,

C. S. Mott Children's Hospital, Room 3-231,

Department of Radiology,

University of Michigan Health System,

1540 E. Hospital Drive, Ann Arbor, MI 48109-4252, USA repaired. The tales told are heartbreaking. It is very understandable why families are devastated. The proper social and judicial response to many cases of child abuse is debatable. Are the consequences appropriate? Is the child (and other children at risk) adequately protected? Is the outcome in the best interest of the child and the family? Are appropriate measures taken to heal and rehabilitate the family environment? Are criminal charges and sentences appropriate? As a society, these questions need to be continually addressed. As uncomfortable as these questions are, however, there is no justification for denying the very existence of child abuse.

Denialism of child abuse is a huge problem that threatens the responsible care of children and families, and it is getting worse. Child abuse denialism is not new. It goes back to the time of Ambroise Tardieu's work in France in the 1860s [10-12], John Caffey's seminal paper in 1946 [13, 14] and C. Henry Kempe's landmark paper in 1962 [15, 16]. Nonetheless, in current times denialism swells. Child abuse denialism has as its base a very small number of physicians who perpetuate false science while ignoring the bulk of the scientific literature and the experience of the overwhelming majority. The child abuse denialists come from various disciplines - radiology, pathology, pediatrics, endocrinology, neurosurgery, emergency medicine, orthopedic surgery, even psychiatry. The names are familiar, they reference one another in the literature and they show up in court, often together and all too frequently. The tactics of denialists are well established: (1) manufacture doubt, (2) identify alleged conspiracies, (3) create impossible expectations of research, (4) use false experts, (5) misrepresent logical fallacies, (6) selectively cite the literature [17-19]. The denialists create the appearance of scientific and medical controversy when, in almost all cases, there is none. Rather than providing clarification, the denialists' tactics are to confuse judges and jurors, to bias the news media and to mislead the public. 
With regard to the osseous findings of child abuse, information propagated by the denialists within the literature and court proceedings is blatantly false and misleading. They call normal bones rickets. They call classic metaphyseal fractures -i.e. bucket handle fractures, or corner fractures-i.e. rickets, even when they are asymmetrical. They call healing rib fractures "Looser zones." They call normal physiological flaring of anterior ribs rickets. They call normal cupping of the distal ulna rickets. They call normal sutures of the skull "craniotabes" and rickets. These descriptions are at odds with many decades of research, extensive literature and the enormous experience base of innumerable radiologists and other physicians. Unfortunately, denialist claims regarding child abuse neurotrauma are even more contentious and challenging to deal with. This is a problem.

Participation by the denialists in the legal adjudication of child abuse is a growing threat to the health care of children and the well-being of children and families. The court system seems ill-equipped to properly censure the denialists in spite of their deceitful and unethical behavior. Ideally, the legal system would practice peer-review by unbiased observers, but this does not occur. Institutions that harbor denialists, whether they be private practices or esteemed academic institutions, should carefully consider their employment. Denialism is tarnishing the name of several prominent academic institutions. Licensing bureaus could have a role by limiting practice. Admirably, the British General Medical Council has curtailed the activity of some rogue witnesses who were dubiously deemed medical experts [20]. Finally, professional societies must carefully consider whether the unethical activity of these denialists challenges the missions and by-laws of the organization [21, 22]. If an organization's mission is to improve the health care and well-being of children and families, it should question condoning the activities of denialists by allowing them to continue membership and to continue to use society membership as evidence of expertise. The American Association of Neurological Surgeons is applauded for censuring one such denialist for documented and repeated unethical behavior [23]. Unfortunately, the threat of litigation, or more correctly, the threat of monetary costs to respond to such litigation even when frivolous, effectively quashes similar actions.

Journal editors and reviewers must be vigilant but openminded. Debate is healthy and new ideas are encouraged; however, poor science, fabrication and perpetuation of unsubstantiated hypotheses pose a substantive threat to the integrity of our medical literature. Publications by child abuse denialists, no matter how poorly done, no matter how flawed, are often used repeatedly in subsequent literature and in subsequent legal activity. A rogue review of evidence-based medicine in shaken baby syndrome by Donahoe [24] is one such paper. It is an understatement to say that Donahoe's review is severely flawed $[25,26]$. Nonetheless it is repeatedly referenced by denialists without proper attention to its crucial flaws or its subsequent criticism in the literature [27-30]. Another example is a commentary on rickets from 2008 published in Pediatric Radiology [31]. The article was published as a commentary and not as an original article because it lacked scientific validity. It was published with a lengthy counterpoint commentary from the editors of the journal pointing out its many inaccuracies [32]. A subsequent letter to the editor from a child abuse pediatrician involved in three of the four cases from the commentary echoed the inaccuracies noted by the editors and pointed out misrepresentation and omission of facts and misconduct by the authors of the rickets commentary [33]. Nonetheless the rickets commentary has been routinely cited in subsequent denialist papers and is undoubtedly cited in legal proceedings [27, 34-38]. The accompanying editorial and subsequent letter are conveniently, deceptively and unethically ignored. Finally, a recently published and very unfortunate paper criticized the seminal work of Kleinman et al. on metaphyseal fractures [34]. Rather than evidence against high-specificity child abuse fractures, the paper is a study in denialism and is riddled by inaccuracies and misinformation [39-41]. It is counter to a wealth of literature and scientific investigation and the experience of the overwhelming majority. Undoubtedly, this paper will also be widely used in legal proceedings by the denialists. It has already been referenced by other denialist papers [35-37].

Unfortunately, medical journals as a whole seem inefficient at properly dispelling the denialist papers, and they continue to appear. The reader of such articles, whether a medical professional or a layperson, must also be vigilant. The legal system is extremely poor at triaging literature, and the growing cache of denialist literature is becoming increasingly difficult to counter. Disappointingly, this even extends to the Supreme Court of the United States [42, 43]. Those in the legal system whose sole interest is to establish the innocence of the accused glom on to the denialist literature [44, 45]. Similarly, biased or misguided news media repeatedly paint a very inaccurate picture of the science of child abuse [46]. Ironically, while purportedly motivated to protect the innocent, the denialists and their supporters serve to put the truly innocent at most risk.

As professionals, our approach is unbiased and based upon sound science and collective experience. Child abuse must be diagnosed when it presents. Other diagnoses are always considered and must be recognized and differentiated from child abuse when they present. Certainty or uncertainty of the diagnosis of child abuse is honestly expressed. In general, physicians involved in the diagnosis of suspected child abuse take inordinate care to get the diagnosis right and to avoid false accusations.

In this issue, we publish a critical review on child abuse fractures and vitamin D deficiency authored by an ad hoc group drawing from the Society for Pediatric Radiology 
Child Abuse Committee and experts in related fields, including child abuse pediatrics, endocrinology and metabolism, and the law [47]. This review is a critical and insightful look into the radiology of child abuse and its differential diagnoses in the musculoskeletal system. As a result of the unwarranted attention and misinformation brought by denialists, the review emphasizes the distinction between child abuse fractures and rickets and vitamin D deficiency. Very appropriately, the review comments on the presentation of these concepts in the legal arena. Readers will be served by better understanding these concepts and issues because they will likely be challenged by them in clinical practice or in court.

These are very difficult times. As physicians dedicated by the Hippocratic Oath, we must remain vigilant to the compassionate care and well-being of children and their families.

Acknowledgments The author thanks Brian D. Coley, MD for his review and comments.

\section{Compliance with ethical standards}

Conflicts of interest None

\section{References}

1. U.S. Department of Health and Human Services (2015) Child maltreatment 2013 https://www.acf.hhs.gov/sites/default/files/cb/ cm2013.pdf. Accessed 17 Dec 2015

2. Chevignard MP, Lind K (2014) Long-term outcome of abusive head trauma. Pediatr Radiol 44:S548-S558

3. Barlow KM, Thomson E, Johnson D et al (2005) Late neurologic and cognitive sequelae of inflicted traumatic brain injury in infancy. Pediatrics 116:e174-e185

4. Peterson $\mathrm{C}, \mathrm{Xu} \mathrm{L}$, Florence $\mathrm{C}$ et al (2014) The medical cost of abusive head trauma in the United States. Pediatrics 134:91-99

5. Fang X, Brown DS, Florence CS et al (2012) The economic burden of child maltreatment in the United States and implications for prevention. Child Abuse Negl 26:156-165

6. Wolfe D (1999) Child abuse: implications for child development and psychopathology. In: Kazdin AE (ed) Developmental clinical psychology and psychiatry, vol 10, 2nd edn. Sage Publications, Thousand Oaks

7. Weeks R, Widom CS (1998) Self-reports of early childhood victimization among incarcerated adult male felons. J Interpers Violence 13:346-356

8. Lisak D, Beszterczey S (2007) The cycle of violence: the life histories of 43 death row inmates. Psychol Men Masculinity 8:118-128

9. Widom CS (1989) The cycle of violence. Science 244:160-166

10. Tardieu A (1860) Étude médico-légale sur les sévices et mauvais traitements exercés sur des enfants [A medico-legal study of cruelty and brutal treatment inflicted on children]. Ann d'Hgyiène Publique Médicine Lég 13:361-398

11. Tardieu A (1868) Étude médico-légale sur l'infanticide [A medicolegal study on infanticide]. Librairie JB Baillière et Fils, Paris
12. Labbé J (2005) Ambroise Tardieu: the man and his work on child maltreatment a century before Kempe. Child Abuse Negl 29: 311-324

13. Caffey J (1946) Multiple fractures in the long bones of infants suffering from chronic subdural hematoma. Am J Roentgenol Radium Ther 56:163-173

14. Astley R (1953) Multiple metaphyseal fractures in small children (metaphyseal fragility of bone). Br J Radiol 26:577-583

15. Kempe CH, Silverman FN, Steele BF et al (1962) The batteredchild syndrome. JAMA 181:17-24

16. Hiller HG (1972) Battered or not - a reappraisal of metaphyseal fragility. Am J Roentgenol Radium Ther Nucl Med 114:241-246

17. McKee M (2010) How the growth of denialism undermines public health. BMJ 341:c6950

18. Diethelm P, McKee M (2009) Denialism: what is it and how should scientists respond? Eur J Public Health 19:2-4

19. Greeley CS (2011) A wolf in evidence clothing: denialism in child abuse pediatrics. AAP Grand Rounds 26:24

20. Dyer O (2004) GMC strikes off proponent of temporary brittle bone disease. BMJ 328:604

21. Milunsky A (2003) Lies, damned lies and medical experts: the abrogation of responsibility by specialty organizations and a call for action. J Child Neurol 18:413-419

22. Chadwick DL, Krous HF (1997) Irresponsible testimony by medical experts in cases involving physical abuse and neglect of children. Child Maltreat 2:313-321

23. (2013) Notice of disciplinary actions: member censure. AANS Neurosurgeon 22:1. http://v1 archives.aansneurosurgeon.org/ 210613/8/3268. Accessed 17 Dec 2015

24. Donohoe M (2003) Evidence-based medicine and shaken baby syndrome. Part I: literature review, 1966-1998. Am J Forensic Med Pathol 24:239-242

25. Narang S (2011) A Daubert analysis of abusive head trauma/shaken baby syndrome. Hous J Health L Policy 11:505-633

26. Greeley CS (2010) Infant fatality. Semin Pediatr Neurol 17: 275-278

27. Barnes PD (2001) Imaging of nonaccidental injury and the mimics: issues and controversies in the era of evidence-based medicine. Radiol Clin North Am 49:205-229

28. Gabaeff SC (2011) Challenging the pathophysiologic connection between subdural hematoma, retinal hemorrhage and shaken baby syndrome. West J Emerg Med 12:144-158

29. Miller D, Barnes P, Miller M (2015) The significance of macrocephaly or enlarging head circumference in infants with the triad: further evidence of mimics of shaken baby syndrome. Am J Forensic Med Pathol 36:111-120

30. Barnes PD, Krasnokutsky M (2007) Imaging of the central nervous system in suspected or alleged nonaccidental injury, including the mimics. Top Magn Reson Imaging 18:53-74

31. Keller KA, Barnes PD (2008) Rickets vs. abuse: a national and international epidemic. Pediatr Radiol 38:1210-1216

32. Slovis TL, Chapman S (2008) Evaluating the data concerning vitamin D insufficiency/deficiency and child abuse. Pediatr Radiol 38: 1221-1224

33. Feldman K (2009) Commentary of 'congenital rickets' article. Pediatr Radiol 39:1127-1129

34. Ayoub DM, Hyman C, Cohen M et al (2014) A critical review of the classic metaphyseal lesion: traumatic or metabolic. AJR Am J Roentgenol 202:185-196

35. Miller M, Ward T, Stolfi A et al (2014) Overrepresentation of multiple birth pregnancies in young infants with four metabolic bone disorders: further evidence that fetal bone loading is a critical determinant of fetal and young infant bone strength. Osteoporos Int 25:1861-1873

36. Paterson CR, Ayoub D (2015) Congenital rickets due to vitamin D deficiency in the mothers. Clin Nutr 34:793-798 
37. Paterson CR, Monk EA (2015) Clinical and laboratory features of temporary brittle bone disease. J Pediatr Endocr Metab 27:37-45

38. Paterson CR (2015) Fractures in rickets due to vitamin D deficiency. Curr Orthopaed Practice 26:261-264

39. Wood BP (2014) Commentary on 'A critical review of the classic metaphyseal lesion: traumatic or metabolic?'. AJR Am J Roentgenol 202:197-198

40. Brown SD, Servaes S, Hayes LL (2014) SPR Child Abuse Committee response regarding classic metaphyseal lesion. AJR Am J Roentgenol 202:W1

41. Kleinman PK (2014) Classic metaphyseal lesions. AJR Am J Roentgenol 202:W603

42. Moreno JA, Holmgren B (2013) The Supreme Court screws up the science: there is no abusive head trauma/shaken baby syndrome 'scientific controversy'. Utah Law Rev 2013:1357-1435
43. Cavazos v. Smith 132 S. Ct. 2 (2011) (Justice Ginsburg, dissenting)

44. Tuerkheimer D (2009) The next innocence project: shaken baby syndrome and the criminal courts. Wash U L Rev 87:1-58

45. Findlay KA, Barnes PD, Moran DA et al (2012) Shaken baby syndrome, abusive head trauma, and actual innocence: getting it right. Hous J Health L Policy 12:209-312

46. Bazelon E (2011) Shaken-baby syndrome faces new questions in court. New York Times Magazine. http://www.nytimes.com/2011/ 02/06/magazine/06baby-t.html. Accessed 17 Dec 2015

47. Servaes S, Brown SD, Choudhary AK et al (2016) The etiology and significance of fractures in infants and young children: a critical multidisciplinary review. Pediatr Radiol. doi:10.1007/s00247-0163546-6 